ISSN. 2775-4324 (Online)

Journal of Physical Activity and Sports

Volume 2, Nomor 2, Agustus 2021, 195-203

Journal of Physical Activity and Sports

\title{
EFEKTIFITAS LATIHAN NEBRASKA AGILITY DRILL DAN SHUTTLE RUN UNTUK MENINGKATKAN KELINCAHAN DRIBBLE DALAM PERMAINAN SEPAKBOLA PADA SSB PUTRA RAYUNG KUSUSMA
}

\author{
Dwicky Nurma Hendra Data \\ ${ }^{1}$ Universitas PGRI Semarang \\ Email : Dwickynhd@gmail.com
}

\begin{abstract}
Footballers at SSB Putra Rayung Kusuma tend to make mistakes when dribbling the ball that is not maximal in training and in mini-game conditions, the athlete is not placed in the right position, he should be placed with the athlete's ability, because the coach only obeys the athlete's wishes for positioning. Therefore, the researcher intends to analyze the Nebraska Agility Drill and shuttle run on Ssb footballer Putra Rayung Kusuma to find out the footballer's talent.The research method used by the author is an experimental method. The characteristic in this design is the presence of a control group. The type of data used in this study is premier data. The premiere data in this study were obtained directly from observations at SSB Putra Rayung Kusuma. Based on the results of the $t$ test, it shows that there is no difference between the two training methods, with $t$ count $0.49>t$ table 1.73 with a significance value $\mathrm{p}$ of $0.67>0.05$, this result shows that there is no difference between the post-test group A and group B. Based on the results of the analysis shows that the increase in the percentage of group A is better than group B, and the average post-test for group A is 17.00 and group B is 17.20 with an average difference of 0.20 . Thus the hypothesis which reads "The Nebraska Agility Drill training method is more effective for increasing dribble agility in soccer for athletes aged 12-14 years than shuttle run training", Thus, it can be concluded that the Nebraska Agility Drill Method is more effective for increasing dribble agility in football for athletes aged 12-14 years than shuttle run training with an average difference of 0.20.
\end{abstract}

Keywords: Nebraska Agility Drill, Shutle Run, Driblle Agility, Football

\begin{abstract}
Abstrak
Pesepakbola di SSB Putra Rayung Kusuma cenderung melakukan kesalahan-kesalahan saat dribble bola yang kurang maksimal dalam berlatih dan dalam kondisi mini game, atlet tidak di tempatkan pada posisi semestinya, dia seharusnya di tempatkan dengan kemampuan yang dimiliki oleh atlet, karena pelatih hanya menuruti keinginan atlet untuk penempatan posisi. Maka dari itu peneliti bermaksut untuk menganalisa Nebraska Agility Drill dan shuttle run pada pesepakbola Ssb Putra Rayung Kusuma untuk mengetahui bakat pesepakbola tersebut. Metode penelitian yang digunakan penulis adalah metode eksperimen. Karakteristik dalam desain ini adalah adanya sebuah kelompok kontrol. Jenis data yang digunakan dalam penelitian ini merupakan data premier. Data premier pada penelitian ini diperoleh secara langsung dari hasil pengamatan di SSB Putra Rayung Kusuma. Berdasarkan hasil uji $t$ menunjukkan tidak adanya perbedaan dari dua metode latihan, dengan $t$ hitung $0.49>\mathrm{t}$ tabel 1.73 dengan nilai signifikansi $\mathrm{p}$ sebesar $0.67>0.05$, maka hasil ini menunjukkan tidak ada perbedaan antara post-test kelompok A dan kelompok B .Berdasarkan hasil analisis menunjukkan bahwa kenaikan presentase kekompok A lebih baik dari kelompok B, dan rata-rata post-test kelompok A sebesar 17.00 dan kelompok B sebesar 17.20 dengan selisih rata-rata 0.20. Dengan demikian hipotesis yang berbunyi "Metode latihan Nebraska Agility Drill lebih efektif untuk peningkatan kelincahan dribble dalam sepakbola atlet usia 1214 tahun daripada latihan Shuttle run". Dengan demikian dapat disimpulkan Metode Nebraska Agility Drill lebih efektif untuk peningkatan kelincahan dribble dalam sepakbola pada atlet usia 12-14 tahun daripada latihan Shuttle run dengan selisih rata-rata sebesar 0.20 .
\end{abstract}

Kata kunci : Nebraska Agility Drill,Shutlle Run,Kelincahan Driblle,Sepak Bola 


\section{PENDAHULUAN}

Sepakbola merupakan salah satu cabang olahraga yang memiliki banyak fans masyarakat. Sepakbola dikenal dan digemari oleh seluruh lapisan masyarakat dunia. Olahrga ini terbilang mudah untuk dimainkan yang juga bias menjadi sarana hiburan. Sepakbola pun menjadi salah satu olahraga yang membantu kesehatan jasmani dan rohani.Sebagai salah satu olahraga dari beberapa olahraga yang selalu masuk ke dalam olimpiade, sepakbola tentu memiliki teknik tersendiri dalam memainkannya. Sama halnya dengan jenis olahraga yang lainnya, sepakbola memiliki teknik yang cukup mudah untuk dilakukan oleh semua kalangan, muda,tua, laki-laki maupun wanita. Semuanya bisa mempelajari dan berlatih sepakbola dengan teknik yang ada di dalamnya Hidayat Wintono. (2017:

3) Sekolah sepak bola Putra Rayung Kusuma adalah sebuah tim yang berdomisili di daerah kabupaten Grobogan tepanya di kecamatan Pulokulon Desa Panunggalan. Desa Panunggalan merupakan desa yang memperhatikan minat bakat anak-anak yang menyukai olahraga sepak bola maka dari itu terbentuklah Ssb Putra Rayung Kusuma. Kegiatan latihan sepak bola dilaksanakan di lapangan desa panunggalan

\section{METODE}

Metode penelitian kuantitatif dapat diartikan juga sebagai metode penelitian yang berlandaskan pada filsafat positivi, digunakan untuk meneliti pada populasi atau sampel tertentu, pengumpulan data menggunakan instrumen penelitian, penelitian ini menggunakan metode penelitian eksperimen. Suharsimi Arikunto (2010: 9) mengatakan bahwa eksperimen adalah suatu cara untuk mencari hubungan sebab akibat (hubungan kausal) antara dua faktor yang sengaja ditimbulkan oleh peneliti dengan mengeliminasi atau mengurangi menyisihkan faktor-faktor lain yang mengganggu.

Untuk memperlancar proses penelitian maka diperlukan sebuah desain penelitian sebagai pedoman bagi peneliti dalam melaksanakan setiap langkah langkah penelitian yang akan diambil agar proses penelitian berjalan sesuai dengan group pretest-posttest design. Desain ini digunakan untuk penelitian eksperimen. Menurut Arikunto (2002: 78) mengungkapkan "two group pre-test post-test prosedur yang benar. Desain penelitian yang digunakan adalah two design adalah penelitian ini dilakukan sebanyak dua kali yaitu sebelum eksperimen (pre-test) dan sesudah ekperimen (post-test) dengan satu kelompok subjek". Desain ini dapat digambarkan sebagai berikut: 
ISSN. 2775-4324 (Online)

Journal of Physical Activity and Sports

Volume 2, Nomor 2, Agustus 2021, 195-203

Journal of Physical Activity and Sports

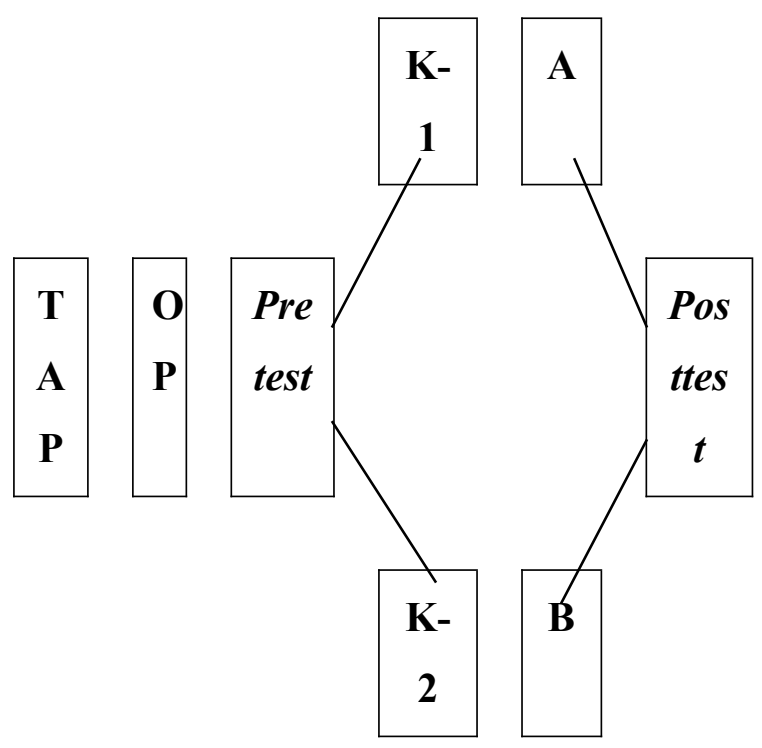

Gambar 2.1Desain Penelitian

(Arikunto, $2013: 124)$

Keterangan:

$>$ TAP $\quad$ Tes awal diikuti semua populasi penelitian

$>$ OP : Ordinal pairing

$>$ Pretest : Tes awal dribble

$>$ K-1 :Kelompok Nebraska Agility Drill

$>$ K-2 : Kelompok Shuttle run

$>$ A :TreatmentNebraska Agility Drill

$>$ B :Treatment Shuttle run

$>$ Posttest :Tes akhir dribble

Maka dengan ini perlu diuji signifikansinya dengan menggunakan rumus I-test rumus pendek (short metode) rumus ini dipersiapakn untuk menyelesaikan penyelidikan eksperimen yang menggunakan pre-test and post-test group (Arikunto, 2013:1)

\section{Sampel}

Jika peneliti akan meneliti sebagian dari populasi, maka penelitian tersebut disebut penelitian sampel. Menurut Sugiyono (2007: 118) mengatakan sampel adalah bagian dari jumlah dan karakteristik populasi tersebut. Sampel yang digunakan dalam penelitian ini sebanyak 30 pesepakbola.Teknik pengambilan sampel dalam penelitian ini menggunakan teknik purposive sampling yang termasuk dalam non probality sampling. Menurut Sugiyono (2007: 124), purposive sampling. 
Efektifitas Latihan Nebraska Agility Drill Dan Shuttle Run Untuk Meningkatkan Kelincahan Dribble Dalam Permainan Sepakbola Pada Ssb Putra Rayung Kususma .....Dwicky Nurma Hendra Data

Dengan demikian kelompok tersebut sebelum diberi perlakuan kemampuan yang sama. Apabila pada post-test nanti terdapat peningkatan keterampilan gerak dasar passing, maka hal ini disebabkan oleh pengaruh perlakuan yang diberikan. Adapun pembagian kelompok dalam penelitian ini dengan cara ordinal pairing sebagai berikut:

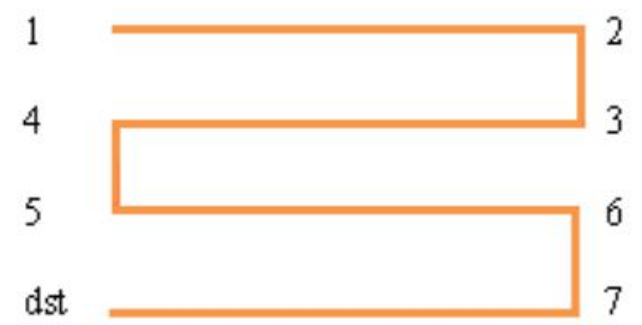

\section{HASIL DAN PEMBAHASAN}

\section{HASIL}

Hasil pre-test pada kelompok A diperoleh nilai rata-rata (mean) adalah 19.8 pada kategori sedang dengan nilai SD adalah 2.04, sedangkan nilai rata-rata (mean) post-test pada kelompok A adalah 17 pada kategori baik dengan SD adalah 2.10. Hasil selengkapnya disajikan pada tabel 4.1 sebagai berikut:

Tabel 4.1 Data Hasil Pre-test dan Post-test Kelompok A

\begin{tabular}{|l|l|l|l|}
\hline Nama Subjek & Pre-test & Post-test & Selisih \\
\hline $\mathrm{Sa}$ & 18 & 15 & 3 \\
\hline $\mathrm{Za}$ & 18 & 13 & 5 \\
\hline $\mathrm{Ai}$ & 19 & 16 & 3 \\
\hline $\mathrm{Yg}$ & 19 & 19 & 0 \\
\hline $\mathrm{Ki}$ & 19 & 17 & 2 \\
\hline $\mathrm{Ro}$ & 19 & 16 & 3 \\
\hline $\mathrm{Ca}$ & 20 & 18 & 2 \\
\hline $\mathrm{Ar}$ & 20 & 17 & 3 \\
\hline $\mathrm{Hi}$ & 21 & 20 & 1 \\
\hline $\mathrm{In}$ & 25 & 19 & 6 \\
\hline $\mathrm{Mean}$ & 19.8 & 17 & \\
\hline $\mathrm{SD}$ & 2.04 & 2.10 & \\
\hline
\end{tabular}

Sumber: Data Penelitiuan

Apabila ditampilkan dalam bentuk distribusi frekuensi, data pre-test dan post-test dribble pada atlet usia 12-14 tahun di Ssb Putra Rayung Kusuma kelompok Nebraska Agility Drill meningkat. Dapat dilihat pada tabel 4.2 sebagai berikut: 
ISSN. 2775-4324 (Online)

Journal of Physical Activity and Sports

Volume 2, Nomor 2, Agustus 2021, 195-203

Tabel 4.2 Distribusi Frekuensi Pre-test dan Post-test Kelompok A

\begin{tabular}{|c|c|c|c|c|c|c|c|}
\hline No & $\begin{array}{l}\text { Wakt } \\
\text { (detik }\end{array}$ & & Kategori & $\mathrm{F}$ & $\%$ & $\mathrm{~F}$ & $\%$ \\
\hline 1 & $16,9<$ & & $\begin{array}{l}\text { Sangat } \\
\text { Baik }\end{array}$ & 0 & $0 \%$ & 4 & $44.44 \%$ \\
\hline 2 & $\begin{array}{l}17,00 \\
19,00 \\
\end{array}$ & - & Baik & 6 & $66.66 \%$ & 5 & $55.55 \%$ \\
\hline 3 & $\begin{array}{l}19,01 \\
21,00\end{array}$ & - & Sedang & 3 & $33.33 \%$ & 1 & $11.11 \%$ \\
\hline 4 & $\begin{array}{l}21,01 \\
23,00 \\
\end{array}$ & - & Kurang & 0 & $0 \%$ & 0 & $0 \%$ \\
\hline \multirow[t]{2}{*}{5} & $23>$ & & $\begin{array}{l}\text { Sangat } \\
\text { Kurang }\end{array}$ & 1 & $11.11 \%$ & 0 & $0 \%$ \\
\hline & & & & 10 & $100 \%$ & 10 & $100 \%$ \\
\hline
\end{tabular}

Sumber: Data Penelitian

Berdasarkan tabel 4.2, hasil pre-test dan post-test dribble pada atlet usia 16-18 tahun di Ssb Putra Rayung Kusuma kelompok Nebraska Agility Drill juga meningkat. Febuari 2020 sampai tanggal 3 Maret 2020. Subjek pada penelitian ini yaitu anak-anak SMA Negeri 2 Kendal yang dalam kategori umur 15-17 yang berjumlah 15 anak, pada saat pelaksanaan pengambilan data pretest dan posttest saya di bantu oleh Muhammad hibatul wafi.

\section{Pre-test dan Post-test Kelompok B (Shuttle Run)}

Hasil pre-test pada kelompok B diperoleh nilai rata-rata (mean) adalah 19.60 pada kategori sedang dengan nilai SD adalah 1.50, sedangkan nilai rata-rata (mean) post-test pada kelompok A adalah 17.20 pada kategori baik dengan SD adalah 1.93. Hasil selengkapnya disajikan pada tabel 4.3 sebagai berikut:

Tabel 4.3 Data Hasil Pre-test dan Post-test Kelompok A

\begin{tabular}{|l|l|l|l|}
\hline Nama Subjek & Pre-test & Post-test & Selisih \\
\hline $\mathrm{Ga}$ & 18 & 16 & 2 \\
\hline $\mathrm{De}$ & 18 & 14 & 4 \\
\hline $\mathrm{Ke}$ & 19 & 15 & 4 \\
\hline $\mathrm{Fr}$ & 19 & 18 & 1 \\
\hline $\mathrm{Fn}$ & 19 & 19 & 0 \\
\hline $\mathrm{Da}$ & 19 & 16 & 3 \\
\hline $\mathrm{Fe}$ & 20199 & 17 & 3 \\
\hline
\end{tabular}




\begin{tabular}{|l|l|l|l|}
\hline $\mathrm{Ik}$ & 20 & 18 & 2 \\
\hline $\mathrm{Ru}$ & 21 & 19 & 2 \\
\hline $\mathrm{Ra}$ & 23 & 20 & 3 \\
\hline Mean & 19.60 & 17.20 & \\
\hline $\mathrm{SD}$ & 1.50 & 1.93 & \\
\hline & & & \\
\hline
\end{tabular}

Sumber: Olah Data Penelitian

Apabila ditampilkan dalam bentuk distribusi frekuensi, data pre-test dan post-test kelincahan dribble pada atlet usia 12-14 tahun di Ssb Putra Rayung Kusuma kelompok Shuttle run meningkat. Dapat dilihat pada tabel 4.2 sebagai berikut:

Tabel 4.4 Distribusi Frekuensi Pre-test dan Post-test Kelompok A

\begin{tabular}{|l|l|l|l|l|l|l|}
\hline No & Waktu (detik) & Kategori & F & $\%$ & F & $\%$ \\
\hline 1 & $16,9<$ & Sangat Baik & 0 & $0 \%$ & 4 & $44.44 \%$ \\
\hline 2 & $17,00-19,00$ & Baik & 6 & $66.66 \%$ & 5 & $55.55 \%$ \\
\hline 3 & $19,01-21,00$ & Sedang & 3 & $33.33 \%$ & 1 & $11.11 \%$ \\
\hline 4 & $21,01-23,00$ & Kurang & 1 & $11.11 \%$ & 0 & $0 \%$ \\
\hline 5 & $23>$ & Sangat Kurang & 0 & $0 \%$ & 0 & $0 \%$ \\
\hline & & & 10 & $100 \%$ & 10 & $100 \%$ \\
\hline
\end{tabular}

Sumber: Olah Data Penelitian

Berdasarkan tabel 4.4, hasil pre-test dan post-test dribble pada atlet usia 12-14 tahun di Ssb Putra Rayung Kusuma kelompok Shuttle run juga meningkat.

\section{PEMBAHASAN}

Berdasarkan uji t yang telah dilakukan maka dapat diketahui beberapa hal untuk mengambil kesimpulan apakah ada peningkatan kelincahan dribble pada atlet usia 16-18 tahun di SSB PRK Panunggalan setelah mengikuti latihan Nebraska Agility Drill untuk kelompok A dan Shuttle run untuk kelompok B selama 16 kali pertemuan. Hasil penelitian dibahas sebagai berikut: 
ISSN. 2775-4324 (Online)

Journal of Physical Activity and Sports

Volume 2, Nomor 2, Agustus 2021, 195-203

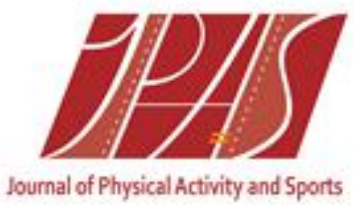

\section{Peningkatan Kelincahan Dribble Kelompok A}

Berdasarkan analisis menunjukkan bahwa latihan Nebraska Agility Drill berpengaruh terhadap peningkatan kelincahan dribble pada atlet usia 12-14 tahun di SSB PRK Panunggalan, dengan bahwa $\mathrm{t}_{\text {hitung }} 5.06>\mathrm{t}$ tabel 1.85 dengan nilai signifikansi $\mathrm{p}$ sebesar $0.001<$ 0.05, maka hasil ini menunjukkan terdapat perbedaan yang signifikan.

\section{Peningkatan Kelincahan Dribble Kelompok B}

Berdasarkan analisis menunjukkan bahwa latihan Shuttle run berpengaruh terhadap peningkatan kelincahan dribble pada atlet usia 12-14 tahun di SSB PRK Panunggalan, dengan bahwa $\mathrm{t}_{\text {hitung }} 6.00>\mathrm{t}$ tabel 1.85 dengan nilai signifikansi $\mathrm{p}$ sebesar $0.000<0.05$, maka hasil ini menunjukkan terdapat perbedaan yang signifikan.

\section{Perbedaan Antara Kelompok A dengan Kelompok B}

Berdasarkan hasil uji t menunjukkan tidak adanya perbedaan dari dua metode latihan, dengan $\mathrm{t}$ hitung $0.49>\mathrm{t}$ tabel 1.73 dengan nilai signifikansi $\mathrm{p}$ sebesar $0.67>0.05$, maka hasil ini menunjukkan tidak ada perbedaan antara post-test kelompok A dan kelompok B .Berdasarkan hasil analisis menunjukkan bahwa kenaikan presentase kekompok A lebih baik dari kelompok B, dan ratarata post-test kelompok A sebesar 17.00 dan kelompok B sebesar 17.20 dengan selisih rata-rata 0.20. Dengan demikian hipotesis yang berbunyi "Metode latihan Nebraska Agility Drill lebih efektif untuk peningkatan kelincahan dribble dalam sepakbola atlet usia 12-14 tahun daripada latihan Shuttle run", diterima.

Pada kelompok A, yaitu eksperimen dengan latihan Nebraska Agility Drill meningkat lebih baik dari kelompok B, karena pada kelompok B yaitu shuttle run yang terjadi pada saat latihan atlet merasa jenuh dan bosen karena latihan terlalu lama jika dibandingkan kelompok A. Kejenuhan tersebut kadang membuat atlet kurang bersemanjat dalam melakukan latihan, sehingga hasilnya dibawah jika dibandingkan dengan kelompok A. Atlet juga kurang termotivasi dalam melakukan latihan passing pemain.

\section{KESIMPULAN}

Berdasarkan hasil analisis data, deskripsi, pengujian hasil penelitian., dan pembahasan dapat diambil kesimpulan, yaitu:

1. Efektifitas latihan Nebraska Agility Drill terhadap peningkatan kelincahan dribble pada atlet usia 12-14 tahun di SSB PRK Panunggalan, dengan $\mathrm{t}$ hitung $5.06>\mathrm{t}$ tabel 1.85 dengan nilai signifikansi $\mathrm{p}$ sebesar $0.001<0.05$ dengan kenaikan presentase $9.98 \%$. 
Efektifitas Latihan Nebraska Agility Drill Dan Shuttle Run Untuk Meningkatkan Kelincahan Dribble Dalam Permainan Sepakbola Pada Ssb Putra Rayung Kususma .....Dwicky Nurma Hendra Data

2. Efektifitas latihan Shuttle run terhadap peningkatan kelincahan dribble pada atlet usia 12-14 tahun di SSB PRK Panunggalan, dengan $\mathrm{t}$ hitung $6.00>\mathrm{t}$ tabel 1.85dengan nilai signifikansi p sebesar $0.000<0.05$ dengan kenaikan presentase $9.92 \%$.

3. Metode Nebraska Agility Drill lebih efektif untuk peningkatan kelincahan dribble dalam sepakbola pada atlet usia 12-14 tahun daripada latihan Shuttle run dengan selisih rata-rata sebesar 0.20 .

\section{DAFTAR PUSTAKA}

Arikunto, Suharsimi. 2002. Prosedur Penelitian Suatu Pendekatan Praktek Edisi Revisi VI. Jakarta. PT Rineka Cipta Charlim, dkk

Dosen FPIPSKR UPGRIS. (2017). Pedoman Penulisan Skripsi 2017. Universitas PGRI Semarang

Harsono. 2001. Latihan Kondisi Fisik. Bandung. FPOK UPI

Harsono. 2015. Kepelatihan Olahraga. Bandung. PT. Remaja Rosda Karya

Hasanah. 2009. Sepakbola. Jakarta. PT Indah Adi Pratama

Herwin. 2004. Sepakbola modern. Diktat Yogyakarta. FIK

Hidayat, Witono. 2017. Buku Pintar Sepak Bola. Jakatra Timur. Anugrah

Jupri Edho Imastra Wardana. (2017). Pengaruh Latihan Permainan Target terhadap Ketepatan Shooting Menggunakan Kaki Bagian Dalam Pemain Futsal SFC Planet Sleman. Skripsi. FIK UNY

Luxbacher. 2011. Sepakbola Langkah-langkah Menuju Sukses. Jakarta. PT Raja Frafrindo Persada

Ma'mun, Amung dan Yudha. 2000. Perkembangan Gerak dan Belajar Gerak. Direktorat Jendral Pendidkikan Dasar Mengajar Komarudin. 2011. Dasar Gerak Sepakbola. FIK UNY

Mielke. 2007. Dasar - dasar Sepakbola. Bandung. Pakar Raya

Muhajir. 2007. Pendidikan Jasmani Olahraga dan Kesehatan Jilid I. Jakarta. Departemen Pendidikan Nasional

Safari. 2012. Pembinaan Kebugaran Jasmani. Bandung. CV Bintang Warli Artika

Sucipto. 2000. Sepakbola. Departemen Pendidikan Nasional 
ISSN. 2775-4324 (Online)

Journal of Physical Activity and Sports

Volume 2, Nomor 2, Agustus 2021, 195-203

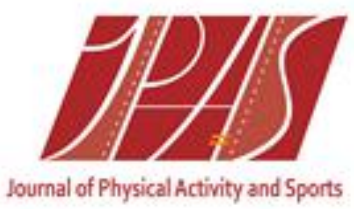

Sugiyono. 2007. Metode Penelitian Kuantitatif, Kualitatif dan R\&D. Bandung. Alfabeta.

Sugiyono. 2010. Metode Penelitian Kuantitatif, Kualitatif dan R\&D. Bandung. Alfabeta.Sukadiyanto. 2005. Pengantar Teori dan Melatih Fisik. Yogyakarta. FIK UNY

Sukatamso. 2002. Teknik Dasar Bermain Sepak bola. Surakarta. Tiga Serangkai

Susanto, Teguh. 2016. Buku Pintar Olahraga. Yogyakarta. Pustaka Baru Pres 